\title{
$\mathrm{M}|\mathrm{R}| \mathrm{S}$ Internet Journal Nitride Semiconductor Research
}

\section{Growth Mode and Defects in Aluminum Nitride Sublimed on (0001) 6H-SiC Substrates}

\author{
Lianghong $\mathrm{Liu}^{1}$, B. Liu ${ }^{1}$, Y. Shi ${ }^{1}$ and J.H. Edgar ${ }^{1}$ \\ ${ }^{1}$ Kansas State University, Department of Chemical Engineering,
}

(Received Wednesday, February 21, 2001; accepted Thursday, March 29, 2001)

The effect of substrate preparation on the sublimation growth of $\mathrm{AlN}$ at about $1800{ }^{\circ} \mathrm{C}$ and 400 torr on (0001) $6 \mathrm{H}-\mathrm{SiC}$ was investigated. The AlN grew in the step flow growth mode on an off-axis $6 \mathrm{H}-$ $\mathrm{SiC}$ substrate with a $6 \mathrm{H}-\mathrm{SiC}$ epilayer, an island growth mode on as-received substrates, and a 2-D growth mode on substrates first coated with an AIN epitaxial layer by MOCVD. Cracks in the deposited AIN crystal due to the lattice and thermal expansion coefficient mismatches were always observed by SEM and optical microscopy.

\section{Introduction}

Group-III nitrides (AlN, GaN, InN, and their alloys) have attracted great interest recently for their enormous potential for optoelectronic device applications operating in the spectral range from green to ultraviolet. The lack of bulk crystals for substrates is a major limitation for fully implementing such devices; the epitaxial growth of nitrides is currently limited to foreign substrates, mainly sapphire and SiC [1]. Bulk crystal AlN will provide a superior substrate for group-III nitride epitaxial layers as it is closely lattice and thermal expansion matched to $\mathrm{GaN}$. It has many favorable properties such as high thermal conductivity, low thermal expansion coefficient, high electrical resistivity, good dielectric properties, and excellent oxidation resistance.

Most studies of AlN bulk crystal growth have employed the sublimation method, as AlN's high melting temperature $\left(>2700^{\circ} \mathrm{C}\right)$ makes it impossible to grow from melt [2] [3] [4] [5]. A bulk AlN crystal of 470 $\mathrm{mm}^{3}$ was produced by self-seeding in the sharp tip of a sealed tungsten crucible by Slack and McNelly [4] during mid-70s. The group of Schowalter and Slack et al. [6] [7] continues to improve on this technique and have reported producing crystals up to $19 \mathrm{~mm}$ in diameter. $6 \mathrm{H}-\mathrm{SiC}$ substrates offer an alternative method of seeding even larger AlN crystals by sublimation due to the easy nucleation and crystal orientation control. Balkas et al. [8] grew seeded single crystalline platelets of AlN less than $1 \mathrm{~mm}$ thick on a $10 \times 10 \mathrm{~mm}^{2} 6 \mathrm{H}-\mathrm{SiC}$ in a resistively heated graphite furnace. Growth rates up to $0.5 \mathrm{~mm} / \mathrm{hr}$ were achieved at $2150 \sim 2250^{\circ} \mathrm{C}$ and a nitrogen pressure of 500 torr. However, the AlN films contained individual hexagonal crystals $\left(\approx 2 \times 2 \mathrm{~mm}^{2}\right)$, and $\mathrm{Si}, \mathrm{C}$ and $\mathrm{O}$ were incorporated into the $\mathrm{AlN}$, from the $\mathrm{SiC}$ coated graphite crucible. Sarney et al. [9] also grew AlN on $6 \mathrm{H}-\mathrm{SiC}$ between $2150^{\circ} \mathrm{C}$ and $2200^{\circ} \mathrm{C}$, with nitrogen pressures of 400 410 torr. The growth rate was varied between 10 and $50 \mu \mathrm{m} / \mathrm{h}$. But the same problems still exist, i.e. the AlN cracks and contains high screw dislocation density due to the stress caused by the thermal expansion coefficients mismatch. Karpov's group [10] [11] grew AlN layers 60 to $80 \mu \mathrm{m}$ thick of $10 \times 10$ $\mathrm{mm}^{2}$ size on $6 \mathrm{H}-\mathrm{SiC}$ as the seed at $1700 \sim 2300^{\circ} \mathrm{C}$ under both atmospheric pressure and in vacuum $\left(10^{-4}\right.$ torr $)$. No characterization of these crystals was presented. In short, AlN deposited on SiC generally has high dislocation densities and multiple small size grains. Thus more research work is necessary to improve growth technique.

A thorough investigation of the growth mode and defects for AlN sublimated on the SiC substrates prepared by different techniques is critical for preparing high quality bulk crystals free of cracks and screw dislocations. In this paper, we focus on the crystal growth mode and defects in AlN grown on different (0001) 6H$\mathrm{SiC}$ substrates. The effects of the substrate preparation on the growth mode and types of defects presented are examined in detail.

\section{Experimental}

\subsection{Sublimation Apparatus}

The experimental setup for AIN sublimation, which is shown in Figure 1, was described in detail in the previous work [12]. Briefly, the $\mathrm{Al}$ and $\mathrm{N}_{2}$ vapor created by 
the dissociation of the hot polycrystalline AlN source (Ts $\sim 1900^{\circ} \mathrm{C}$ ) are transported to a seed held at a lower temperature $\left(\mathrm{Tc} \sim 1800^{\circ} \mathrm{C}\right)$ in a $30 \mathrm{~mm}$ diameter tungsten crucible. Then adsorption/desorption takes place at the seed crystal surface leading to growth. The sublimation is carried out in ultra-high purity $\mathrm{N}_{2}$. The temperature and temperature gradient are maintained by a resistively heated tungsten element and the pressure is automatically maintained at a constant value (400 torr). Sintered AlN with approximate $0.6 \mathrm{wt} \%$ oxygen as the main impurity (as analyzed by a standard inert gas fusion method) was the source material. Growth runs varying from 10 minutes to 40 hours were employed.

The in-situ growth temperature was measured by the same optical pyrometer focused on the top lid of the retort and controlled by the output power.

\subsection{Substrate Preparations}

$6 \mathrm{H}-\mathrm{SiC}$ single crystals of various orientations and surface preparation were used, to determine their influence on the AlN growth mode. There was almost no growth on C-face substrates, thus only $\mathrm{Si}$-face $\mathrm{SiC}$ substrates were used, including on-axis as-received (0001) SiC, on-axis (0001) $\mathrm{SiC}$ with an AlN buffer layer deposited by MOCVD, on-axis (0001) $\mathrm{SiC}$ with a 3C-SiC epitaxial layer, off-axis as-received (0001) $\mathrm{SiC}$, off-axis (0001) $\mathrm{SiC}$ with an AlN buffer layer deposited by MOCVD, and off-axis (0001) SiC with a 6H-SiC epitaxial layer.

The AlN buffer layer was grown in a vertical MOCVD induction heated reactor. Trimethylaluminum (TMA) and ammonia $\left(\mathrm{NH}_{3}\right)$ were utilized as $\mathrm{Al}$ and $\mathrm{N}$ sources, and Pd-cell purified $\mathrm{H}_{2}$ was the carrier gas. The epilayer was deposited at $1000^{\circ} \mathrm{C}$ and 80 torr under the $\mathrm{H}_{2}, \mathrm{NH}_{3}$ and TMA flow rates of $6 \mathrm{slm}, 3 \mathrm{slm}$ and 60 sccm respectively. An approximate $1.5 \mu \mathrm{m}$ thick AlN film was obtained for 2 hours run.

The $\mathrm{SiC}$ epitaxial layer was grown at horizontal-type atmospheric pressure CVD. After etching in a mixture of hydrogen and $\mathrm{HCl}$ at $1400^{\circ} \mathrm{C}, \mathrm{SiC}$ epitaxial layers were deposited at $1400 \sim 1500^{\circ} \mathrm{C}$ with a silane $\left(\mathrm{SiH}_{4}\right)$ flow rate $0.5 \mathrm{sccm}$, ethylene $\left(\mathrm{C}_{2} \mathrm{H}_{4}\right)$ flow rate $0.7 \mathrm{sccm}$, and $\mathrm{H}_{2}$ flow rate $8 \mathrm{slm}$. An approximate $1.0 \mu \mathrm{m}$ thick $6 \mathrm{H}-\mathrm{SiC}$ film on off-axis $6 \mathrm{H}-\mathrm{SiC}$ or $3 \mathrm{C}-\mathrm{SiC}$ film on onaxis $6 \mathrm{H}-\mathrm{SiC}$ was deposited in 30 minutes.

\subsection{Morphology Characterization Techniques}

Macrostuctrual features in the AlN crystals were characterized by Nomarski differential interference contrast microscopy. The surface morphology was examined by scanning electron microscopy (SEM) up to 2000x. Steps and terraces in the surface morphology of some samples were examined by atomic force microscopy (AFM) in contact mode.

\section{Results and Discussion}

\subsection{As-received On-axis and Off-axis $6 \mathrm{H}$-SiC}

On on-axis and off-axis as-received $6 \mathrm{H}-\mathrm{SiC}$ substrates, the AlN deposited in an island growth mode promoted by screw dislocations. The AlN grains were $1 \mathrm{~mm}$ to $2 \mathrm{~mm}$ in size after several ten hours of growth. Hexagonal sub-grains and grain boundaries are clearly evident in the optical micrograph for AlN deposited on such substrates (Figure 2).

Screw dislocations provide the steps for the growth of crystal. The terrace width between steps is about 0.3 $\mu \mathrm{m}$, as determined by SEM image shown in Figure 3, and the step height was about $20 \mathrm{~nm}$, as determined by AFM. This shows that the diffusion length of $\mathrm{Al}$ or $\mathrm{N}$ atoms on the surface is too small to enhance a 2-dimensional nucleation and growth. The large thermal stress between substrates and deposited AIN results in high screw dislocation density. Figure 4 (a) and (b) show the surface of AlN nucleated on the on-axis and off-axis asreceived $\mathrm{SiC}$ substrates. The randomly nucleated hexagonal hillocks (black spots) on the $\mathrm{SiC}$ surface gradually merged together as AlN growth progressed. This merging produced the grain boundaries seen in Figure 2.

The large stress introduced by the cooling from sublimation temperature to the room temperature, cracked the AlN into small pieces several $\mathrm{mm}$ in size. Occasionally the $\mathrm{SiC}$ substrate peeled off from thicker bulk AlN crystal, as shown in Figure 5. The cracks in the AlN crystal did not coincide with the boundaries of subgrains. At higher temperature $\left(>1840^{\circ} \mathrm{C}\right)$, the AlN surface became more rough, and several holes appeared on surface due to substrate decomposition. Figure 6 shows a SEM image of an AlN film grown on on-axis $6 \mathrm{H}-\mathrm{SiC}$ substrate at $1890^{\circ} \mathrm{C}$ and 400 torr for 20 hours. Cracks, holes and even grains are apparent in the AlN film.

\subsection{On-axis and Off-axis $6 \mathrm{H}-\mathrm{SiC}$ with AIN buffer layer}

An AlN buffer layer is commonly used in the GaN epitaxy on $\mathrm{SiC}$ substrate, to promote the wetting of substrate surface. In the sublimation growth of AlN, an AlN buffer layer significantly changed the growth mode and decreased the screw dislocations. Figure 7 (a) and (b) show the surface morphology of AlN grown on the onaxis and off-axis $6 \mathrm{H}-\mathrm{SiC}$ at $1780^{\circ} \mathrm{C}, 400$ torr for 10 hours with AlN buffer layer deposited at $1100^{\circ} \mathrm{C} 80$ torr for 3 hours. The rings are interference patterns caused by stress in the films, and the black lines are cracks. The surface of the AlN film on the on-axis substrate is smoother than on the off-axis $\mathrm{SiC}$, where parallel steps are distributed regularly on the growth surface.

As expected, the AlN epilayer (about $1.5 \mu \mathrm{m}$ ) changed the growth mode of AlN sublimated on the $\mathrm{SiC}$ substrate. Figure 8 (a) and (b) show the surface of AlN 
nucleated on the on-axis and off-axis $\mathrm{SiC}$ substrates. In these thin films (about $20 \mu \mathrm{m}$ thick), the cracks were regularly located in the $(10 \overline{1} 0)$ plane, i.e. in $\langle 11 \overline{2} 0\rangle$ direction. No hexagonal-shaped nuclei or steps were detected on the surfaces, thus AlN deposition by sublimation on AlN-buffered SiC substrates occurred in a 2$\mathrm{D}$ growth mode. The mechanism of this growth change may result from two factors: (1) the AlN buffer layer prevented $\mathrm{SiC}$ decomposition, which generates many irregular steps or hillocks on the substrate surface functioned as nucleation sites; (2) AlN buffer layer changed the surface energy or wetting of the substrates to the sublimation growth.

Although AlN crystals grown on the $\mathrm{SiC}$ with an AlN buffer layer had much lower dislocations, cracks were still inevitable in these experimental runs with AlN layers less than about $400 \mu \mathrm{m}$ thick, as shown in Figure 9. The growth mode may change with the increase of thickness, which is encountered in III-nitride epitaxy especially for quantum dots fabrication [13] [14]. Efforts are still taken to grow pure thicker and larger AlN crystals in 2-D growth mode.

\subsection{On-axis and Off-axis $6 \mathrm{H}-\mathrm{SiC}$ with $\mathrm{SiC}$ epitaxial layer}

Wilson et al. [15] found that deposition of AlN epilayers on off-axis $6 \mathrm{H}-\mathrm{SiC}$ and $4 \mathrm{H}-\mathrm{SiC}$ with an initial $\mathrm{SiC}$ epilayer displayed high quality step flow growth. The APCVD epitaxial growth of off-axis $\mathrm{SiC}$ resulted in uniform steps with height of $1.5 \mathrm{~nm}$, i.e. 6 bilayers and narrow step width of about $70 \mathrm{~nm}$ compared with about average $200 \mathrm{~nm}$ of singular substrate in our experiments. As-received off-axis $6 \mathrm{H}-\mathrm{SiC}$ and on-axis $6 \mathrm{H}-\mathrm{SiC}$ have various step heights of different number of layers as well as non-uniform step width according to our AFM examination. Step bunching occurs when an additional epitaxial $\mathrm{SiC}$ layer was deposited on the initial off-axis substrate. The step bunching brings about 6-bilayer step height and uniform step width due to the different growth rate of different stacking layer.

Figure 10 shows the morphology of AlN nucleation and growth on the on-axis and off-axis $\mathrm{SiC}$ substrates with about $1 \mu \mathrm{m} \mathrm{SiC} \mathrm{epitaxial} \mathrm{layers.} \mathrm{Hexagonal} \mathrm{hill-}$ ocks were still observed on the on-axis substrates with $3 \mathrm{C}-\mathrm{SiC}$ epilayer while step flow growth is clearly displayed on the off-axis substrates with $6 \mathrm{H}-\mathrm{SiC}$ epilayer.

Unfortunately, we could not keep step flow growth mode at initial nucleation stage on off-axis substrates for long time (>10 hours). The step bunching happened during the step flow growth. The SEM observation shown in Figure 11 indicates that hexagonal nucleation was taking place in the wide terrace or at the edges of the steps, which is attributed to the low mobility of AlN.

\section{Summary and Conclusion}

The effects of substrate misorientation and buffer layers (both $\mathrm{SiC}$ and $\mathrm{AlN}$ ) on the morphology of AlN deposited on $6 \mathrm{H}-\mathrm{SiC}$ were analyzed. On-axis and off-axis $6 \mathrm{H}-$ $\mathrm{SiC}$ wafers without any treatment, or with AlN buffer layers, or with $\mathrm{SiC}$ epilayers, have been utilized as the substrates for AlN sublimation growth.

The AlN sublimated on the on-axis and off-axis $6 \mathrm{H}-$ $\mathrm{SiC}$ substrate without any treatment proceeded by island growth, producing a high density of screw dislocations. This produced individual AlN grains and rough surface morphologies. These problems were largely eliminated by first depositing an AlN layer on the $6 \mathrm{H}-\mathrm{SiC}$ by MOCVD before starting sublimation growth. 2-dimensional growth was achieved on the $6 \mathrm{H}-\mathrm{SiC}$ with AlNbuffered layers and no screw dislocations were observed. At last, growth on off-axis $\mathrm{SiC}$ with $6 \mathrm{H}-\mathrm{SiC}$ epilayers had the step flow growth mode, but with the increasing of step width, hexagonal nucleation hillocks deposited on terraces.

Step width played an important role on the growth mode. Different growth modes were attributed to the low mobility of AlN adatoms on crystal surface. In our growth condition, the surface mobility may be too low to annihilate the domain boundary at large step width such as several hundred $\mathrm{nm}$. Increasing temperature is a way to solve this problem. But the temperature is twoedged sword, it can not only increase the surface mobility and hence the grain size, but also enhance the decomposition of $\mathrm{SiC}$ and hence contaminate the AlN crystal.

\section{ACKNOWLEDGMENTS}

The financial support of the Office of Naval Research through grants number N00014-97-1-0332 and N00014-99-1-0104 is gratefully appreciated.

\section{REFERENCES}

[1] B. Monemar, J. Mater. Sci. 10, 227 (1999).

[2] B. Krukowska-Fulde, T. Niemyski, Electron Tech. 3, 3 (1970).

[3] T. Ishii, T. Sato, M. Iwata, Miner. J. 6, 323-342 (1971).

[4] G. A. Slack, T. F. McNelly, J. Cryst. Growth 34, 263 (1976).

[5] M Tanaka, S Nakahata, K Sogabe, H Nakata, M Tobioka, Jpn. J. Appl. Phys. 36, L1062 (1997).

[6] Leo J Schowalter, Juan C Rojo, Nikolai Yakolev, Yuriy Shusterman, Katherine Dovidenko, Rungjun Wang, Ishwara Bhat, Glen A Slack, MRS Internet J. Nitride Semicond. Res. 5S1, W6.7 (2000).

[7] L. J. Schowalter, Y. Shusterman, R. Wang, I. Bhat, G. Arunmozhi, G. A. Slack, Appl. Phys. Lett. 76, 985 (2000).

[8] C. M. Balkas, Z. Sitar, T. Zheleva, L. Bergman, R. Nemanich, R. F. Davis, J. Cryst. Growth 179, 363 (1997). 
[9] Wendy Lynn Sarney, Lourdes Salamanca-Riba, Tim Hossain, P. Zhou, H N Jayatirtha, Hyoung Ho Kang, R. D. Vispute, Michael Spencer, Ken Jones, MRS Internet J. Nitride Semicond. Res. 5S1, W5.5 (2000).

[10] S.Yu. Karpov, D.V. Zimina, Yu.N. Makarov, E.N. Mokhov, A.D. Roenkov, M.G. Ramm, Yu.A. Vodakov, Phys. Stat. Sol. A 176, 435-438 (1999).

[11] A.S. Segal, S.Yu. Karpov, Yu.N. Makarov, E.N. Mokhov, A.D. Roenkov, M.G. Ramm, Yu.A. Vodakov, J. Cryst. Growth 211, 68-72 (2000).

[12] L. Liu, J. H. Edgar, J. Cryst. Growth 220, 243 (2000).

[13] Robert F. Davis, Satoru Tanaka, R. Scott Kern, J. Cryst. Growth 163, 93-99 (1996).

[14] B. Daudin, G. Feuillet, G. Mula, H. Mariette, J. L. Rouviere, N. Pelekanos, G. Fishman, C. Adelmann, J. Simon, Phys. Stat. Sol. A 176, 621 (1999).

[15] S. Wilson, C.S. Dickens, J. Griffin, M.G. Spencer, MRS Internet J. Nitride Semicond. Res. 4S1, G3.61 (1999).

\section{FIGURES}

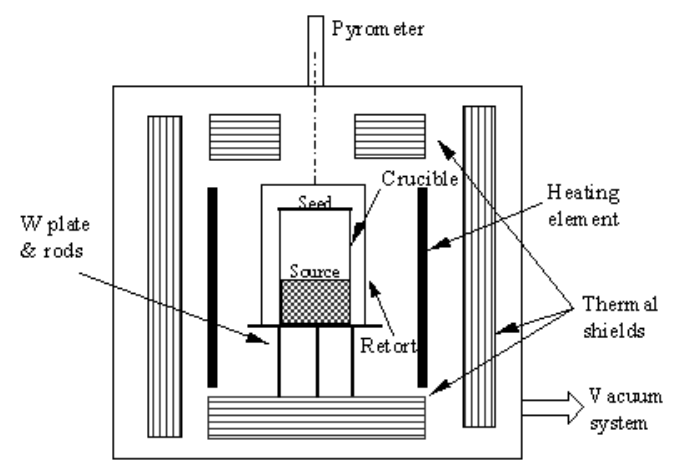

Figure 1. Schematic view of AlN sublimation growth system

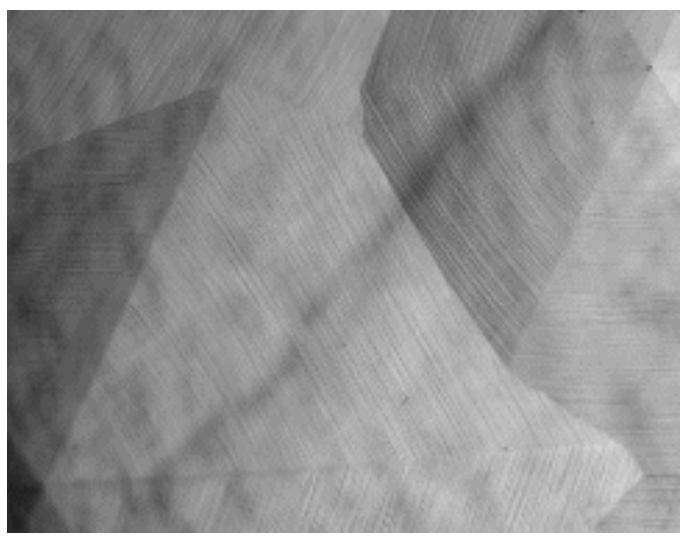

Figure 2. Optical micrograph of AlN crystal surface grown on on-axis, as-received (0001) $6 \mathrm{H}-\mathrm{SiC}$ substrate at $1780{ }^{\circ} \mathrm{C}$ and 400 torr for 40 hours with the magnification $100 \times$ (The real width of the crystal in above image is $1.0 \mathrm{~mm}$ ).

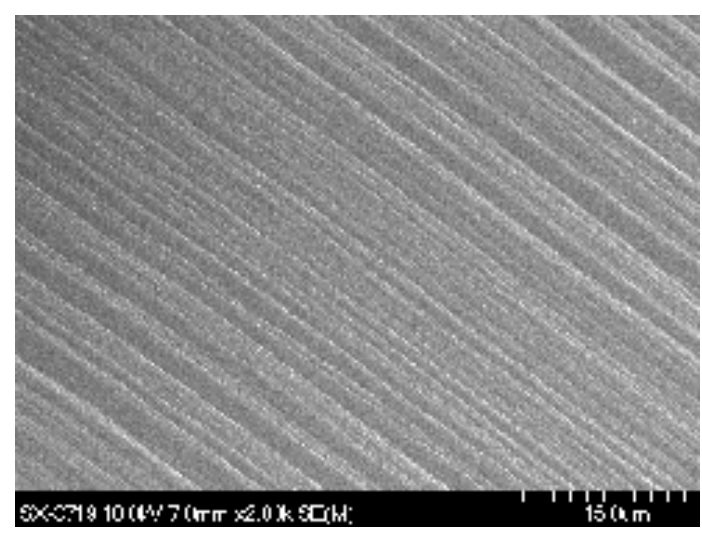

Figure 3. SEM of AlN crystal surface grown on on-axis asreceived (0001) $6 \mathrm{H}-\mathrm{SiC}$ substrate at $1780{ }^{\circ} \mathrm{C}$ and 400 torr for 40 hours with the magnification $2000 \times$.

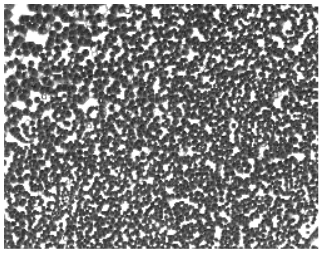

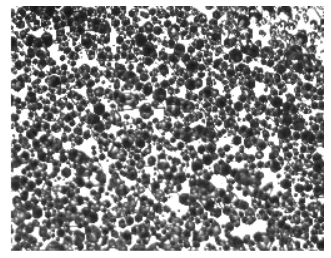

Figure 4. Optical micrograph of AlN crystal grown on asreceived (0001) $6 \mathrm{H}-\mathrm{SiC}$ substrate at $1780^{\circ} \mathrm{C}, 400$ torr for 2 hours with magnification 100×: (a) on-axis (b) off-axis. (The real width of crystal in above image is $1.0 \mathrm{~mm}$ ).

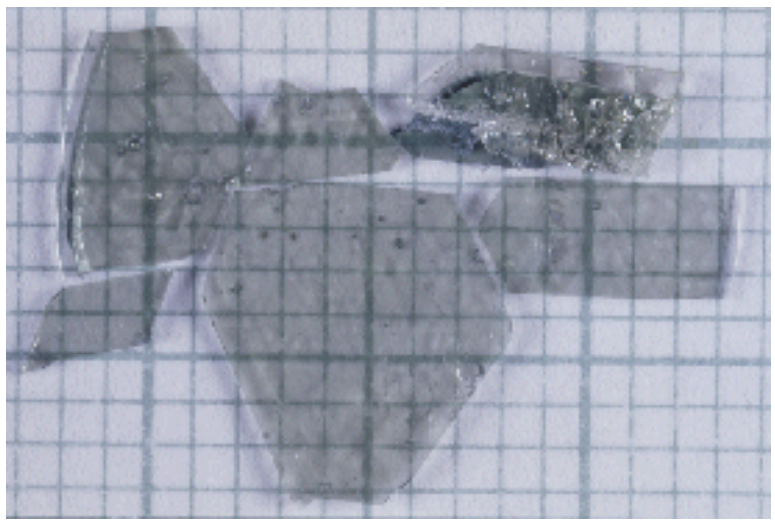

Figure 5. AlN bulk crystals peeled off from the on-axis, asreceived (0001) 6H-SiC substrate on which they were deposited. The crystals were grown at $1780^{\circ} \mathrm{C}$ and 400 torr for 40 hours (grid size is $1 \mathrm{~mm}$ ) 


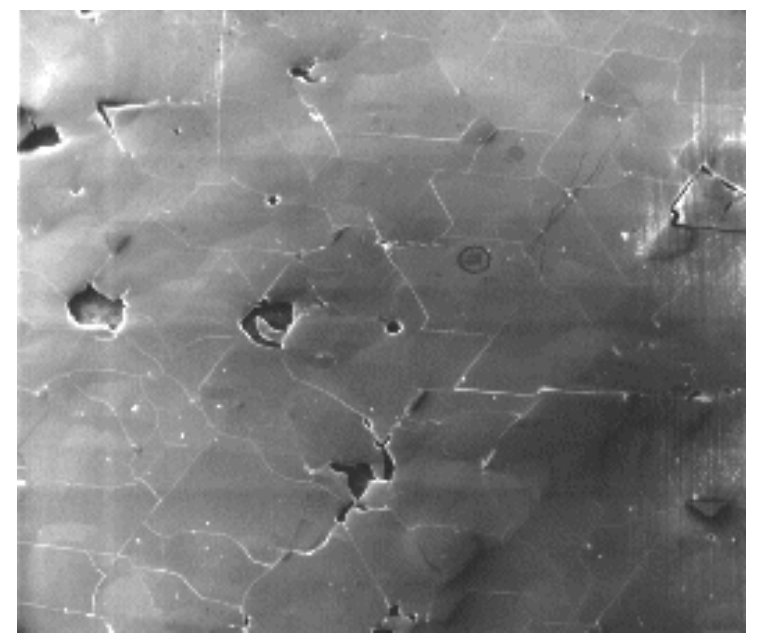

Figure 6. SEM of AlN grown on on-axis as-received (0001) 6H$\mathrm{SiC}$ substrate at $1890^{\circ} \mathrm{C}$ and 400 torr for 20 hours with magnification $20 \times$ (real width of above crystal is $1.0 \mathrm{~cm}$ ).

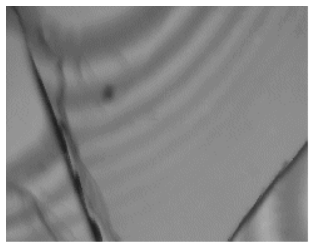

(a)

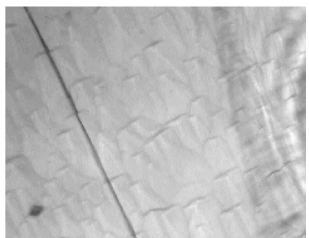

(b)
Figure 7. Optical micrograph of AlN crystal surface grown at $1780^{\circ} \mathrm{C}$ and 400 torr on (0001) $6 \mathrm{H}-\mathrm{SiC}$ substrate for 10 hours with an AlN epitaxial layer. The magnification is 100x: (a) onaxis, (b) $8^{\circ}$ off-axis. (The real width of crystal in above image is about $1.0 \mathrm{~mm}$ ).

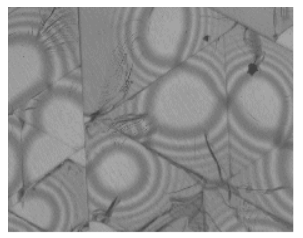

(a)

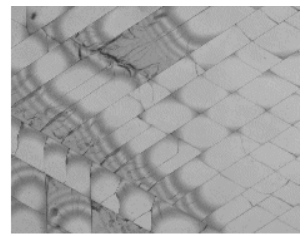

(b)
Figure 8. Optical micrograph of AlN crystal grown at $1780^{\circ} \mathrm{C}$, 400 torr for 2 hours on (0001) 6H-SiC substrate with an AlN epitaxial layer. The magnification is 1003: (a) on-axis (b) $8^{\mathrm{O}}$ off-axis. (The real width of crystal in above image is about 1.0 $\mathrm{mm})$.

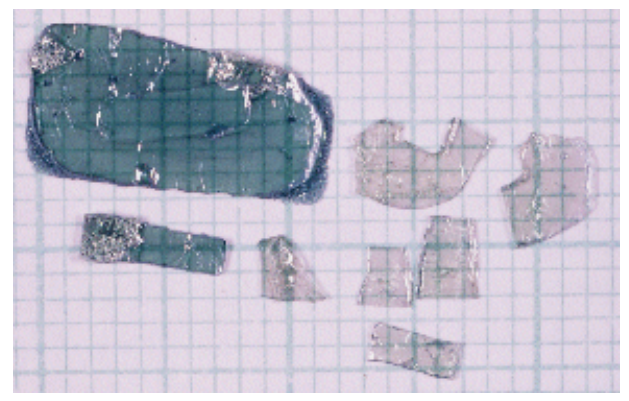

Figure 9. AlN bulk crystal grown on on-axis AlN-buffered (0001) $6 \mathrm{H}-\mathrm{SiC}$ substrate at $1780^{\circ} \mathrm{C}$ and 400 torr for 40 hours (grid size is $1 \mathrm{~mm}$, left big pieces with darker color are peeled $\mathrm{SiC}$ substrate, other smaller ones with light color are peeled AlN).

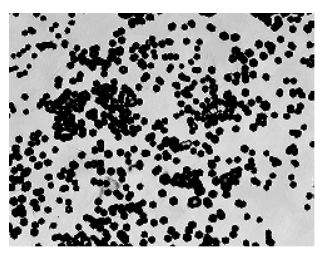

(a)

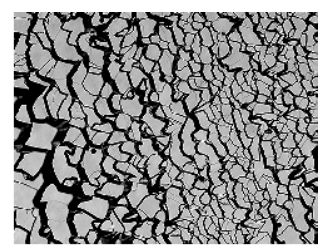

Figure 10. Optical micrograph of AlN crystal grown at $1870^{\circ} \mathrm{C}$, 400 torr for 2 hours on on-axis (0001) $6 \mathrm{H}-\mathrm{SiC}$ substrate with about $1 \mu \mathrm{m} \mathrm{SiC}$ epitaxial layer. The magnification is 1003: (a) on-axis; (b) $8^{\mathrm{o}}$ off-axis. (The real width of film in above image is about $1.0 \mathrm{~mm})$.

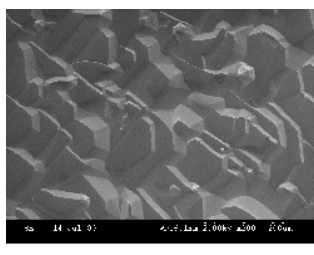

(a)

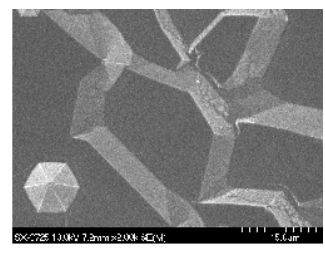

(b)
Figure 11. SEM of AlN grown on $8^{\circ}$ off-axis (0001) $6 \mathrm{H}-\mathrm{SiC}$ substrate with about $1 \mu \mathrm{m} \mathrm{SiC}$ epitaxial layer at $1870^{\circ} \mathrm{C}, 400$ torr for 2 hours with magnification 2000: (a) 200times (b) $2000 \times$. 